\title{
Pesquisa de tecido prostático em pacientes $46, X X$ portadoras da forma clássica de hiperplasia congênita das suprarrenais
}

\author{
Search of prostatic tissue in $46, X X$ congenital adrenal hyperplasia
}

Mariana da Costa Rose Paulino', Leandra Steinmetz' , Hamilton Cabral de Menezes Filho', Hilton Kuperman', Thaís Della Manna', José Gilberto Henriques Vieira², Roberto Blasbalg ${ }^{3}$, Ronaldo Baroni ${ }^{3}$, Nuvarte Setian' ${ }^{1}$, Durval Damiani ${ }^{1}$

Departamento de Endocrinologia Pediátrica, Instituto da Criança do Hospital das Clínicas, Faculdade de Medicina da Universidade de São Paulo (HC-FMUSP), São Paulo, SP, Brasil

${ }^{2}$ Laboratório Fleury, São Paulo, SP, Brasil

${ }^{3}$ Instituto de Radiologia, HC-FMUSP, São Paulo, SP, Brasil
Correspondência para: Mariana da Costa Rose Paulino Av. Araquaia, 437, Parque Rio Grande 09830-110 - São Bernardo do Campo, SP, Brasil marianacrp@hotmail.com

Recebido em 26/Abr/2008 Aceito em 13/Jan/2009

\section{RESUMO}

Objetivos: Verificar a ocorrência de tecido prostático em pacientes portadoras da forma clássica de hiperplasia congênita das suprarrenais, com cariótipo 46,XX e analisar a sensibilidade e a especificidade do antígeno prostático específico (PSA) das pacientes com hiperplasia congênita das suprarrenais em relação à detecção de tecido prostático na ressonância magnética (RNM) de região pélvica. Métodos: Foram estudadas 52 crianças e adolescentes, sendo 32 meninas portadoras da forma clássica de hiperplasia congênita das suprarrenais, 10 meninas e 10 meninos sem hiperplasia congênita das suprarrenais. A RNM da região pélvica e a coleta de PSA, diidrotestosterona e testosterona foram realizadas em todos os pacientes. Para analisar a capacidade de discriminação do antígeno prostático-específico, foi utilizada a curva ROC (receiver operating characteristic curve). Resultados: Cinco das 32 pacientes portadoras de hiperplasia congênita das suprarrenais apresentaram tecido prostático na RNM de região pélvica. Para concentração de antígeno prostático-específico de $0,1 \mathrm{ng} / \mathrm{mL}$, obteve-se sensibilidade de $100 \%$ e especificidade de $88,9 \%$ para a detecção de tecido prostático. Conclusões: A ocorrência de tecido prostático nas pacientes portadoras de hiperplasia congênita das suprarrenais estudadas foi de 15,6\%. O antígeno prostático-específico mostrou ser valioso marcador de tecido prostático nestas pacientes. Arq Bras Endocrinol Metab. 2009;53(6):716-20

Descritores

Hiperplasia congênita das suprarrenais; próstata; antígeno prostático-específico; diidrotestosterona

\section{ABSTRACT}

Objectives: To describe the presence of prostatic tissue in $46, \mathrm{XX}$ patients with the classical form of congenital adrenal hyperplasia (CAH); to evaluate the sensitivity and specificity of prostatic specific antigen (PSA) measured in congenital adrenal hyperplasia patients with regard to the detection of prostatic tissue in pelvic MRI. Methods: We studied 52 children and adolescents, 32 with the classical form of congenital adrenal hyperplasia, 10 boys and 10 girls without $\mathrm{CAH}$. Pelvic MRI was performed in all patients to detect prostatic tissue. Prostate specific antigen, testosterone and dihydrotestosterone were measured in all patients. We used Receiver Operating Characteristic Curve for PSA discrimination capacity. Results: Five girls with congenital adrenal hyperplasia showed image of prostatic tissue on pelvic MRI. Prostate specific antigen showed sensitivity and specificity of $100 \%$ and $88.9 \%$, respectively, taking $0.1 \mathrm{ng} / \mathrm{mL}$ as the cutoff level. Conclusions: The incidence of prostatic tissue in $46, \mathrm{XX}$ patients with the classical form of congenital adrenal hyperplasia was $15.6 \%$. PSA demonstrated to be a good marker of prostatic tissue in these patients and should be used to screen patients to be submitted to image studies. Arq Bras Endocrinol Metab. 2009;53(6):716-20

Keywords

Congenital adrenal hyperplasia; prostate; prostate specific antigen; dihydrotestosterone 


\section{INTRODUÇÃO}

$\mathrm{A}^{\mathrm{h}}$ hiperplasia congênita das suprarrenais (HCSR) é um distúrbio que inclui mutações nos genes que codificam as enzimas responsáveis pela síntese dos esteroides, que resultam comprometimento da síntese do cortisol. Em dois desses defeitos enzimáticos, na deficiência de 21-hidroxilase e 11-hidroxilase, o excesso da produção de andrógenos pelas suprarrenais promove a virilização da genitália externa das meninas afetadas $(1,2)$. Os graus de virilização podem variar de uma discreta clitoromegalia (Prader I) até uma genitália externa totalmente masculinizada (Prader V) (3).

A presença de tecido prostático em pacientes $46, \mathrm{XX}$ portadoras de HCSR já foi relatada por alguns autores. Acredita-se que o desenvolvimento desse tecido decorra do estímulo androgênico, por meio da diidrotestosterona (DHT), sobre as glândulas parauretrais de Skene dessas pacientes. Essas glândulas, presentes em todas as meninas, possuem homologia histológica e enzimática com a próstata masculina $(4,5)$.

Além da presença de tecido prostático nessas pacientes, houve dois relatos de alterações nesse tecido, sendo o primeiro o de uma paciente $46, \mathrm{XX}$ portadora de deficiência de 21-hidroxilase que desenvolveu hiperplasia prostática benigna (6) e outra com a mesma deficiência enzimática que, aos 62 anos, teve o diagnóstico de adenocarcinoma de próstata (7).

Os métodos que podem ser utilizados para a detecção de tecido prostático incluem o antígeno prostático específico (PSA), bem como métodos de imagem (ultrassonografia e ressonância magnética de região pélvica). O PSA é uma glicoproteína de $34 \mathrm{kDa}$ que atua como serina protease e é encontrada quase exclusivamente no epitélio prostático $(8,9)$. O gene do PSA ( $h K L K 3)$ é um membro da família de genes das calicreínas teciduais humanas e é localizado no cromossomo 19, entre os loci $19 q 13.2$ e 19q13.4 (10). Sua grande utilidade clínica foi estabelecida na década de 1980 quando se mostrou que o PSA era marcador útil na detecção e no seguimento de pacientes com carcinoma prostático $(11,12)$.

Em um estudo realizado com 132 meninos em estádios puberais variados (I-V), observou-se correlação positiva significativa entre PSA e testosterona e também entre PSA e estádio puberal (13).

De acordo com os relatos descritos, foi considerada importante a pesquisa de tecido prostático nas pacientes 46,XX portadoras da forma clássica de HCSR em acompanhamento no Ambulatório de Endocrinologia Pediátrica do Instituto da Criança.

\section{PACIENTES E MÉTODOS}

Foram estudadas 32 pacientes portadoras da forma clássica de HCSR, que faziam acompanhamento no Ambulatório de Endocrinologia Pediátrica do Instituto da Criança do Hospital das Clínicas, no período de janeiro de 2004 a agosto de 2006.

Fizeram parte do estudo meninas e adolescentes com HCSR maiores de 6 anos e menores de 22 anos, com média de idade de $11,8 \pm 4,2$ anos.

Trinta e uma dessas pacientes apresentavam deficiência de 21-hidroxilase e uma era portadora de deficiência de 11-hidroxilase, ambas as formas clássicas.

A idade mínima de 6 anos foi escolhida pela maior possibilidade de realização da RNM de região pélvica sem anestesia. Foram excluídas as pacientes com condição clínica impeditiva de realizar exames laboratoriais e/ou imagem, portadoras de outras doenças crônicas ou com suspeita de neoplasias.

Como há poucos estudos sobre o valor normal de PSA em crianças, bem como sobre exames de imagem da região prostática, recrutaram-se 10 meninas e 10 meninos sem HCSR como grupo-controle para a dosagem de PSA, testosterona, DHT e realização de RNM de região pélvica.

As pacientes que foram tomadas como grupo-controle faziam acompanhamento no Ambulatório de Endocrinologia Pediátrica do Instituto da Criança para investigação diagnóstica de baixa estatura ou puberdade precoce. As meninas do grupo-controle apresentavam média de idade de 9,8 $\pm 1,9$ anos, enquanto a média de idade dos meninos do grupo-controle era de 9,3 \pm 2,7 anos.

As pacientes com HCSR ficaram uma semana sem o uso de glicocorticoide antes da coleta, sob estrita vigilância clínica, pois sabe-se que o nível de PSA está correlacionado com o aumento da testosterona.

Os responsáveis pelas pacientes portadoras de HCSR foram informados que elas ficariam uma semana sem a medicação glicocorticoide, sob monitorização. Nenhuma das pacientes apresentou sintomas de insuficiência adrenal durante essa semana sem glicocorticoide. O protocolo de pesquisa foi aprovado pela Comissão de Ética para Análise do Projetos de Pesquisa (CAPPesq) e os responsáveis pelos participantes assinaram o termos de consentimento para a pesquisa.

O PSA foi dosado pelo método eletroquimioluminométrico ultrassensível, com sensibilidade analítica de $0,003 \mathrm{ng} / \mathrm{mL}$ (Elecsys 2010, Roche Diagnóstica, São Paulo). A DHT foi dosada pelo método de radioimunoensaio pós-extração e cromatografia (Vieira, 2002). 
A testosterona foi dosada pelo método imunofluorimétrico Auto Delfia (Wallac, Inc., Turku, Finlândia).

Avaliaram-se a sensibilidade e a especificidade do PSA em relação à deteç̧ão do tecido prostático nas pacientes portadoras da forma clássica de HCSR.

Para analisar a capacidade de discriminação do PSA, foi utilizada a curva ROC (receiver operating characteristic curve).

Os três grupos (meninas com HCSR, meninos normais e meninas normais) foram comparados em relação aos valores de PSA, testosterona e DHT pelo teste de Kruskal-Wallis (ANOVA não paramétrica). Quando houve diferença entre os três grupos, foi realizado o teste de comparações múltiplas de Dunn entre os grupos: meninas com HCSR e meninas-controle, meninas com HCSR e meninos-controle e meninas e meninos-controle.

Utilizaram-se como padrão-ouro as RNMs da região pélvica que foram realizadas no Instituto de Radiologia do Hospital das Clínicas, pelo aparelho de 1,5 tesla, da GE. Os radiologistas analisaram as RNMs de região pélvica em momentos diferentes e eram cegos para as pacientes portadoras de HCSR e para o grupo-controle.

\section{RESULTADOS}

Cinco das 32 pacientes portadoras de HCSR apresentaram tecido prostático na RNM de região pélvica, o que correspondeu à porcentagem de 15,6\% (Figura 1 ). A concordância entre os radiologistas na identificação do tecido prostático foi de $100 \%$.

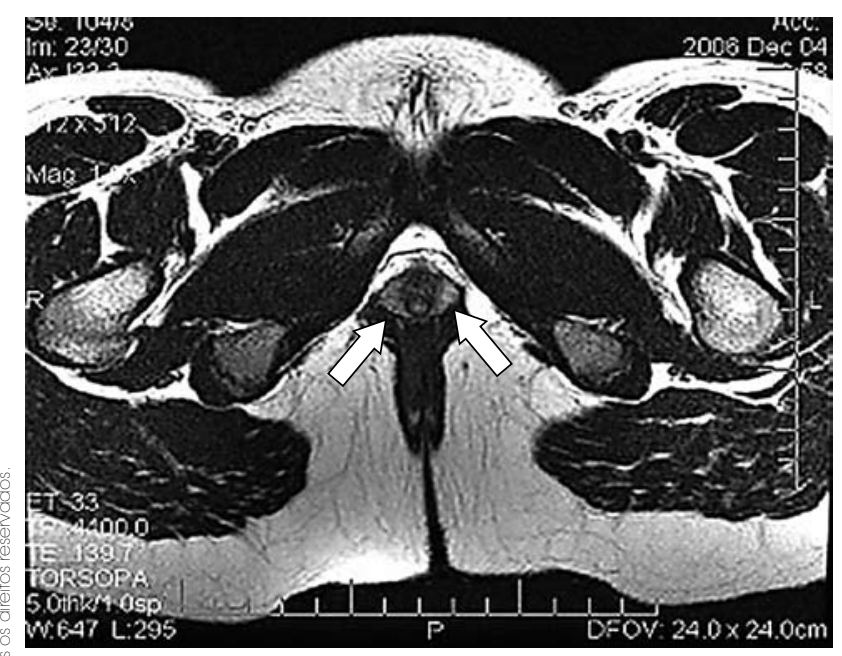

Figura 1. Tecido prostático em paciente 46,XX com HCSR.

A mediana do PSA nas pacientes portadoras de HCSR foi de $0,0235 \mathrm{ng} / \mathrm{mL}, 0,038 \mathrm{ng} / \mathrm{mL}$ nos meninos-controle e $0,003 \mathrm{ng} / \mathrm{mL}$ nas meninas-controle.
Houve diferença estatisticamente significativa entre os três grupos, resultando $\mathrm{p}<0,0008$; entre o grupo das meninas com HCSR e meninas-controle, $\mathrm{p}<0,001$. Porém, não houve diferença entre as meninas com HCSR e os meninos-controle $(\mathrm{p}>0,05)$ e entre as meninascontrole e os meninos-controle $(\mathrm{p}>0,05)$ (Tabela 1$)$.

Tabela 1. Valores de PSA (ng/mL) nas pacientes com HCSR e em meninos e meninas do grupo-controle

\begin{tabular}{cccc}
\hline \multicolumn{5}{c}{ HCSR } \\
\hline$<0,003$ & $\mathbf{0 , 1 1 ^ { * }}$ & 0,027 & 0,037 \\
0,029 & $\mathbf{0 , 2 1}^{*}$ & $<0,003$ & 0,005 \\
0,025 & 0,092 & $\mathbf{0 , 2 8}^{*}$ & $<0,003$ \\
0,055 & 0,038 & 0,016 & 0,020 \\
0,080 & 0,011 & 0,006 & 0,022 \\
$\mathbf{0 , 4 0}$ & $<0,003$ & 0,17 & $<0,003$ \\
0,17 & 0,019 & $<0,003$ & $\mathbf{1 , 3}$ \\
$<0,003$ & 0,029 & $<0,003$ & $<0,003$ \\
\hline Meninos-controle & Meninas-controle \\
\hline$<0,003$ & 0,27 & $<0,003$ & $<0,003$ \\
$<0,003$ & 0,035 & $<0,003$ & $<0,003$ \\
$<0,003$ & $<0,003$ & $<0,003$ & $<0,003$ \\
0,054 & $<0,003$ & $<0,003$ & $<0,003$ \\
$<0,003$ & $<0,003$ & $<0,003$ & $<0,003$ \\
\hline
\end{tabular}

* Valores de PSA das pacientes com HCSR que apresentaram tecido prostático na RNM.

A mediana da testosterona nas pacientes com HCSR foi de $152 \mathrm{ng} / \mathrm{dL}, 9,3 \mathrm{ng} / \mathrm{dL}$ nas meninas do grupocontrole e $8,85 \mathrm{ng} / \mathrm{dL}$ nos meninos do grupo-controle (Figura 2). Houve diferença estatisticamente significativa entre os três grupos $(\mathrm{p}<0,0001)$, entre o grupo das meninas com HCSR e meninas-controle $(\mathrm{p}<0,001)$ e entre as meninas com HCSR e meninos-controle $(\mathrm{p}<$ $0,01)$. Não houve diferença estatística entre as meninas e os meninos-controle $(p>0,05)$.

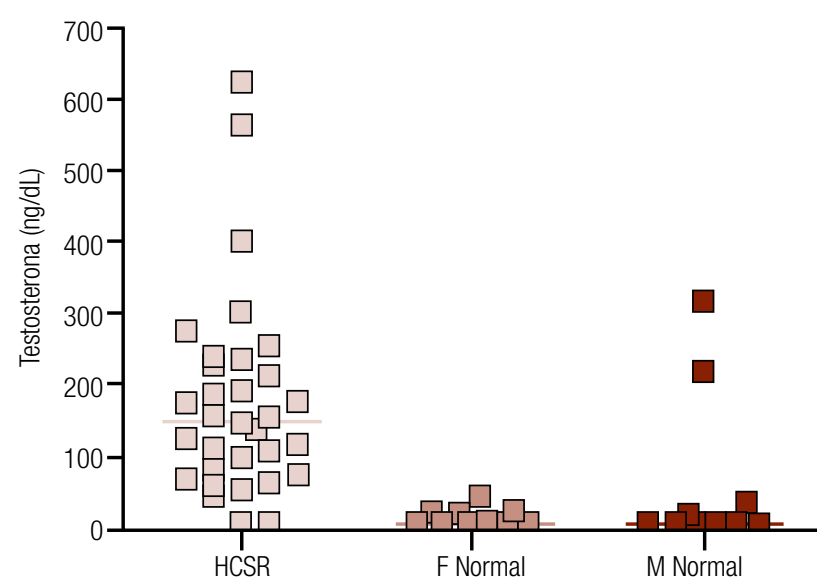

Figura 2. Valores de testosterona nas pacientes com HCSR, meninos e meninas do grupo-controle. 
A mediana da DHT nas pacientes com HCSR foi de $27,7 \mathrm{ng} / \mathrm{dL}, 5,8 \mathrm{ng} / \mathrm{dL}$ nas meninas-controle e 7,1 ng/ dL nos meninos-controle (Figura 3). Houve diferença estatisticamente significativa entre os três grupos $(\mathrm{p}<0,0001)$, entre o grupo das meninas com HCSR e meninas-controle $(\mathrm{p}<0,01)$ e entre as meninas com HCSR e meninos-controle $(\mathrm{p}<0,01)$. Porém, não houve diferença estatística entre as meninas e os meninos-controle $(p>0,05)$.

Tomando-se como ponto de corte a concentração de PSA de $0,1 \mathrm{ng} / \mathrm{mL}$, obtiveram-se sensibilidade de $100 \%$ e especificidade de $88,9 \%$ para a detecção de tecido prostático na RNM de região pélvica (Tabela 2). Por meio da curva ROC, observou-se que a capacidade de discriminação do PSA é elevada (Figura 4).

\section{DISCUSSÃO}

Há evidências de que a hiperestimulação do córtex adrenal pode causar produção excessiva de andrógenos, o que pode promover o crescimento da próstata. No estudo de Walsh e Gittes (14), que versou sobre administração de hormônio adrenocorticotrófico a animais castrados, verificou-se crescimento das glândulas sexuais acessórias.

$\mathrm{O}$ achado de tecido prostático em cinco pacientes das 32 portadoras de HCSR provavelmente deve-se ao excesso de DHT, que promove a proliferação das glândulas parauretrais de Skene, homólogas à próstata masculina. Em situações normais, sem o estímulo androgênico, não ocorre o crescimento das glândulas de Skene durante a vida (15).

O presente estudo demonstrou que o PSA é bom marcador de tecido prostático. Os valores de PSA encontrados nas pacientes portadoras de HCSR foram, na sua maioria, mais elevados do que os do grupo-controle de meninas e meninos. Das 32 meninas portadoras de HCSR, apenas nove apresentaram níveis de PSA indetectáveis. A detecção do PSA na maioria das pacientes com HCSR provavelmente está relacionada à testosterona elevada, pois, como já foi relatado, há correlação positiva entre PSA e testosterona.

Há poucos estudos sobre os níveis de PSA em crianças e adolescentes do sexo feminino. Em 1996, Randell e cols. (16) dosaram o PSA de 374 crianças e adolescentes (196 meninos e 178 meninas), desde recém-nascidos até 18 anos. Entre 1 e 10 anos, houve detecção do PSA em $10 \%$ de meninas e em $11 \%$ dos meninos. Segundo os autores, a ausência de diferença dos níveis de PSA entre os sexos até a puberdade pode ser explicada pela produção de PSA nas meninas por tecidos não-prostáticos.

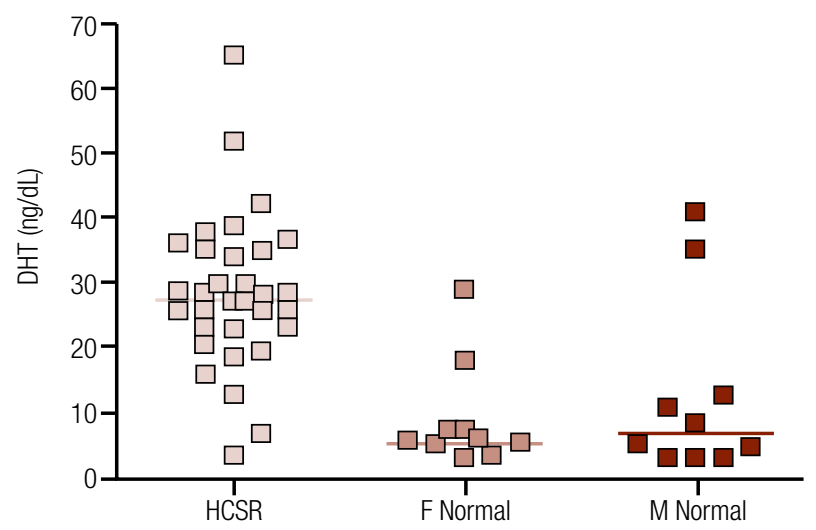

Figura 3. Valores de DHT nas pacientes com HCSR, meninos e meninas do grupocontrole.

Tabela 2. Valores de sensibilidade e especificidade do PSA nas pacientes com HCSR

\begin{tabular}{ccc}
\hline PSA (ng/mL) & Sensibilidade & Especificidade \\
\hline 0,04 & 1,00 & 0,22 \\
0,06 & 1,00 & 0,18 \\
0,08 & 1,00 & 0,14 \\
$\mathbf{0 , 1 0}$ & $\mathbf{1 , 0 0}$ & $\mathbf{0 , 1 1}$ \\
0,14 & 0,80 & 0,11 \\
0,19 & 0,80 & 0,11 \\
0,24 & 0,60 & 0,03 \\
0,27 & 0,60 & 0,00 \\
\hline
\end{tabular}

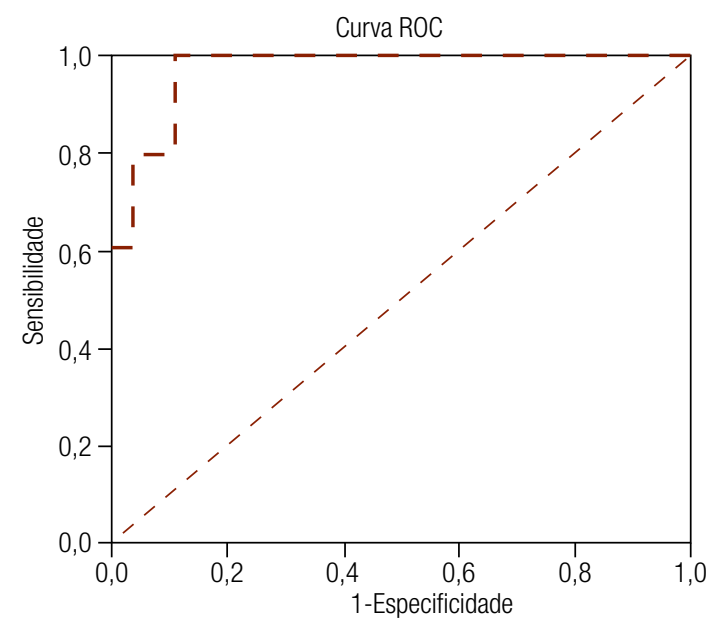

Figura 4. Curva ROC do PSA das pacientes com HCSR.

Antoniou e cols. (10) tomaram como hipótese que os níveis de PSA poderiam ser usados no diagnóstico de doenças urogenitais em crianças. Os níveis de PSA não diferiram significativamente entre meninos e meninas até os 12 anos; após essa idade, houve aumento significativo do PSA nos meninos, 30 vezes o valor correspondente nas meninas, refletindo o desenvolvimento da próstata pelo estímulo androgênico. 
Nas meninas portadoras de HCSR que não apresentaram tecido prostático na RNM de região pélvica, a detecção do PSA pode ser explicada pela produção desta glicoproteína pelas glândulas parauretrais de Skene. Porém, há relatos de PSA detectável em outros locais, como o tecido mamário, tumores de ovário, pulmão ou outros tumores $(8,16)$.

Apesar de a concordância entre os radiologistas ter sido de $100 \%$ em relação à detecção do tecido prostático nas pacientes portadoras de HCSR, todo exame de imagem possui algumas limitações, algumas inerentes ao próprio procedimento e outras em relação ao observador. A capacidade de deteç̧ão de tecido prostático depende de alguns fatores, como tamanho (> $5 \mathrm{~mm}$ ), topografia, sinal e morfologia. Por isso, não se sabe se as três pacientes que tiveram o PSA acima de $0,1 \mathrm{ng} /$ $\mathrm{mL}$ não possuíam realmente o tecido ou se ele não foi identificado na RNM de região pélvica.

Observou-se que o descontrole da doença nas pacientes portadoras de HCSR ocorreu na maioria dos casos em que foi detectado o tecido prostático. O que não se sabe é o tempo necessário de estímulo androgênico para que ocorra o desenvolvimento desse tecido, já que em alguns casos houve bom controle da doença por vários anos, mas mesmo assim houve o desenvolvimento do tecido parauretral após algum período de descontrole da doença. Isso aponta para a existência de outros fatores, além do excesso de andrógenos, para que ocorra o desenvolvimento do tecido prostático. Provavelmente, há variações individuais na sensibilidade das glândulas de Skene aos andrógenos.

Como a ocorrência de tecido prostático, neste estudo, nas pacientes 46,XX portadoras da forma clássica de HCSR mostrou-se elevada $(15,6 \%)$, acredita-se que há necessidade de pesquisá-lo, a fim de prevenir as possíveis complicações advindas da presença desse tecido, como a hiperplasia benigna prostática e o adenocarcinoma de próstata. O acompanhamento evolutivo dessas pacientes poderia ser feito com dosagens de PSA periódicas e, em casos de concentração acima de $0,1 \mathrm{ng} / \mathrm{mL}$, seria recomendável a realização da RNM de região pélvica.
Declaração: os autores declaram não haver conflitos de interesse científico neste estudo.

\section{REFERÊNCIAS}

1. New M. Inborn erros of adrenal steroidogenesis. Mol Cell Endocrinol. 2003;211:75-83.

2. White PC, Speiser PW. Congenital adrenal hyperplasia due to 21hydroxylase deficiency. Endocr Rev. 2000;21:245-91.

3. Damiani D. Abordagem diagnóstica e terapêutica das anomalias da diferenciação sexual. In: Setian N. Endocrinologia pediátrica. $2^{\mathrm{a}}$ ed. São Paulo: Sarvier; 2002. p. 452-9.

4. Tepper SL, Jagirdar J, Heath D, Geller SA. Homology between the female paraurethral (Skene's) glands and the prostate. Arch Pathol Lab Med. 1984;108:423-5.

5. Zaviacic M. The adult human female prostate homologue and the male prostate gland: a comparative enzyme-histochemical study. Acta Histochem. 1985;77:19-31.

6. Heyns C, Rimington D, Kruger T, Falck V. Benign prostatic hyperplasia and uterine leiomyomas in a female pseudohermaphrodite: a case report. J Urol. 1987;137:1245-7.

7. Winters JL, Chapman PH, Powell DE, Banks ER, William RA, Wood DP Jr. Female pseudohermaphroditism due to congenital adrenal hyperplasia complicated by adenocarcinoma of the prostate and clear cell carcinoma of the endometrium. Am J Clin Pathol. 1996;106:660-4.

8. Armbruster DA. Prostate-specific antigen: biochemistry, analytical methods, and clinical application. Clin Chem. 1993;39:181-95.

9. Vihko P, Kurkela R, Ramberg J, Pelkonen I, Vihko R. Time-resolved immunofluorometric assay of human prostate-specific antigen. Clin Chem. 1990;36(1):92-5.

10. Antoniou A, Papanastasiou P, Stephanidis E, Diamandis E, Androulakakis PA. Assessment of serum prostate specific antigen in childhood. BJU Int. 2004;93:838-40.

11. Stamey TA, Yang N, Hay AR, McNeal JE, Freiha FS, Redwine E. Prostate-specific antigen as a serum marker for adenocarcinoma of the prostate. N Engl J Med. 1987;317:909-18.

12. $\mathrm{Yu} \mathrm{H}$, Diamandis E. Ultrasensitive time-resolved immunofluorimetric assay of prostate-specific antigen in serum and preliminary clinical studies. Clin Chem. 1993;39:2106-14.

13. Vieira JG, Nishida SK, Pereira AB, Arraes RF, Verreschi IT. Serum levels of prostate-specific antigen in normal boys throughout puberty. J Clin Endocrinol Metab. 1994;78:1185-7.

14. Walsh PC, Gittes RF. Inhibition of extratesticular stimuli to prostatic growth in the castrate rat by antiandrogens. Endocrinology. 1970;87:624-7.

15. Wernert N, Albrech M, Sesterhenn I, Bonkhoff H, et al. The "female prostate" location, morphology, immunohistochemical characteristics and significance. Eur Urol. 1992;22:64-9.

16. Randell E, Diamandis E, Ellis G. Serum prostate-specific antigen measured in children from birth to age 18 years. Clin Chem. 1996;42:420-3. 